$$
\begin{aligned}
& 1007 \\
& 040864
\end{aligned}
$$

NASA

Technical Memorandum 107448
Army Research Laboratory Technical Report ARL-TR-1397

\title{
JTAGG II Brush Seal Test Results
}

Gul K. Arora

AlliedSignal Engines

Phoenix, Arizona

and

Margaret P. Proctor

Lewis Research Center

Cleveland, Ohio

Prepared for the

33rd Joint Propulsion Conference and Exhibit cosponsored by AIAA, ASME, SAE, and ASEE

Seattle, Washington, July 6-9, 1997
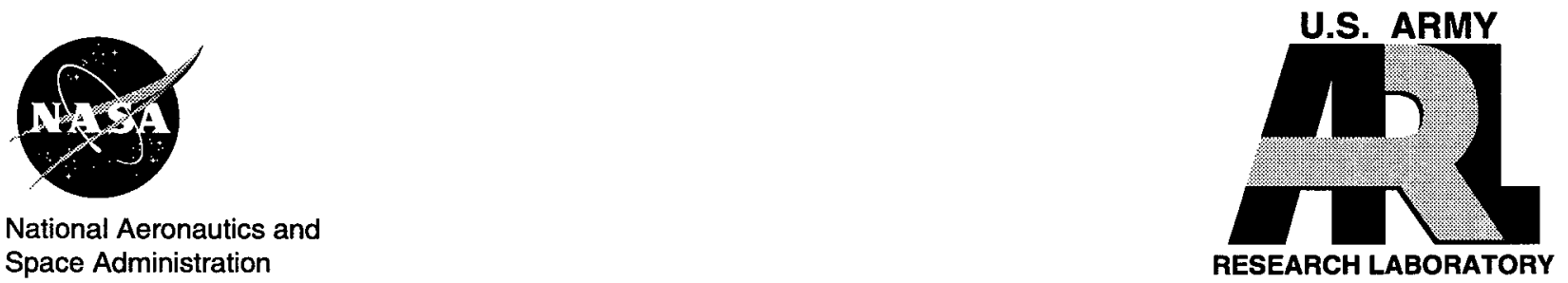


\title{
JTAGG II BRUSH SEAL TEST RESULTS
}

\author{
Gul K. Arora \\ AlliedSignal Engines \\ Phoenix, Arizona 85072-2181 \\ and \\ Margaret P. Proctor \\ National Aeronautics and Space Administration \\ Lewis Research Center \\ Cleveland, Ohio 44135
}

\begin{abstract}
$\underline{\text { Abstract }}$
The Tri-services JTAGG II engine uses two identical brush seals, in tandem, located aft of the high pressure compressor. The engine operating conditions, at intermediate rated power (IRP), for this seal are estimated to be $50000 \mathrm{rpm}(899 \mathrm{ft} / \mathrm{sec})$ speed, $175 \mathrm{psid}$ air to air pressure differential and $1200^{\circ} \mathrm{F}$ air temperature. The testing was comprised of static air leakage, performance, seal offset, rotor run out tests and a $50 \mathrm{hr}$ endurance test in the NASA Lewis seal rig. Based on the test results, it is concluded that the brush seal design should be able to meet the air leakage flow factor goal of less than 0.004 for the engine IRP operating conditions. As a comparison, a labyrinth seal in this location with a 0.005 in. typical radial clearance has an estimated leakage flow factor of 0.007. The long term seal life can not be predicted accurately due to the limited endurance testing of $50 \mathrm{hr}$. However, based on the excellent condition of the test seal and rotor after $50 \mathrm{hr}$ of testing, it is anticipated that the seals should easily meet the JTAGG II engine test requirement.
\end{abstract}

\section{Introduction}

The JTAGG II engine is an advanced gas generator, funded by the U.S. Army, Navy and Air Force, being developed by AlliedSignal Engines in Phoenix. This engine uses two identical brush seals, in tandem, located aft of the high pressure compressor (HPC) as shown in Fig. 1. The two brush seals separate the hot HPC back face cavity from the relatively cooler buffer air for the number 2 forward carbon ring seal. The IRP operating conditions for this seal in the JTAGG II engine are estimated to be $50000 \mathrm{rpm}(899 \mathrm{ft} / \mathrm{sec})$ speed, $175 \mathrm{psid}$ air to air pressure differential and $1200^{\circ} \mathrm{F}$ air temperature. A purchase order was issued to NASA Lewis Research Center to test these two brush seals in a seal rig. These seals were tested between March, 1996 and January, 1997. Because the NASA seal rig did not have the capability to test the seal to maximum engine speed, pressure differential and temperature simultaneously, testing was conducted up to the maximum operating conditions shown in Table I.

Following a description of the test apparatus, the procedures, air leakage and wear results will be discussed for the static, performance, brush seal offset, rotor run out, and endurance tests.

\section{Brush Seal and Rotor Description}

A total of 4 sets of brush seals, each set consisting of two seals, and four rotors were designed and procured for rig testing. A typical test brush seal and its nomenclature is shown in Fig. 2. Two brush seal configurations, conventional low hysteresis and advanced low hysteresis design, were used in testing. The advanced low hysteresis design brush seals were used only in the endurance test, which included pre- and post-endurance performance testing. The seal was designed to have a clearance with the rotor at build and a line to line to slight interference at engine IRP speed of $50000 \mathrm{rpm}$. Brush seal bristle and side plate material were Haynes 214 and INCO 625, respectively. The test rotor shown in Fig. 3 was made of INCO 718 and coated with EG\&G Sealol's proprietary Triboglide coating. Triboglide is essentially a chromium carbide coating with barium calcium fluoride, high temperature solid lubricant, dispersed in the coating. The rotor o.d. is $4.121 \mathrm{in}$. One rotor had a $0.003 \mathrm{in}$. radial run out in its o.d. relative to the i.d. for the rotor run out test. All rotors were balanced at low speed and then trim balanced in the test rig prior to testing with a seal.

\section{Seal Rig Description}

The NASA Lewis seal rig, shown in Fig. 4, was used for testing the brush seals. An adapter was made to fit in the existing seal holder to mount the smaller diameter brush seals for the JTAGG II engine. In addition, a new

This paper is declared a work of the U.S. Government and is not subject to copyright protection in the United States. 
plenum was made to direct the flow to the o.d. of the rotor which was also smaller. An enlarged view of the seal and rotor installation in the NASA Lewis rig is shown in Fig. 5. For the seal offset test, a second adapter was made with a radial offset of $0.003 \mathrm{in}$. between the adapter o.d. and i.d.

\section{$\underline{\text { Static Air Leakage Test }}$}

This test characterized the brush seal air leakage as a function of air to air pressure differential and air temperature under static conditions. Conventional low hysteresis brush seals $\mathrm{S} / \mathrm{N} 1$ and 2 were used in this test as the low pressure side and high pressure side seals, respectively.

\section{Leakage Performance}

Figure 6 shows the air leakage flow factor as a function of pressure drop across the seal at air temperatures of $70,500,800$ and $1100^{\circ} \mathrm{F}$. The flow factor, $\phi$, is defined as follows:

$$
\phi=\dot{m} \times \frac{\sqrt{\left(T_{\text {avg }}+459.67\right)}}{\left(P_{u} \times D_{i}\right)}, \frac{\text { lbm }- \text { in. }-\sqrt{R}}{\text { lbf }-\mathrm{s}}
$$

where

$$
\begin{gathered}
\dot{m}=\text { Air leakage flow rate, } \mathrm{lbm} / \mathrm{sec} \\
\mathrm{T}_{\mathrm{avg}}=\begin{array}{c}
\text { Average air temperature upstream of } \\
\text { the seal pair, }{ }^{\circ} \mathrm{F}
\end{array} \\
\mathrm{P}_{\mathrm{u}} \quad \begin{array}{c}
\text { Air pressure upstream of the seal pair, } \\
\text { psia }
\end{array} \\
\mathrm{D}_{\mathrm{i}} \quad \text { Outside diameter of the seal rotor, } 4.121 \mathrm{in} .
\end{gathered}
$$

As shown in Fig. 6, the flow factor decreases as air temperature increases. This is due to a thermal mismatch between the seal and the rotor, which reduces the clearance at higher temperature. Also at higher temperature, viscosity of the air increases, which offers higher resistance to air flow and therefore a further reduction in air flow rate through the seal. Figure 6 also shows that the flow seems to start choking at about 50 psid (a pressure ratio of about 3.4).

\section{Performance Test}

This test characterized the brush seal air leakage as a function of speed, air to air pressure differential and air temperature. Conventional low hysteresis brush seals S/N 1 and 2 were used in this test as the low pressure side and high pressure side seals, respectively.

\section{Leakage Performance}

Figures 7 to 10 show plots of air leakage flow factor as a function of pressure ratio across the seal pair for speeds from 0 to $45000 \mathrm{rpm}$ at air temperatures of $70,500,800$, and $1100^{\circ} \mathrm{F}$. The pressure ratio, $\mathrm{Pr}$, is defined as follows: $\operatorname{Pr}=\mathrm{P}_{\mathrm{u}} / \mathrm{P}_{\mathrm{d}}$,

where

$\mathrm{P}_{\mathrm{u}}=$ Air pressure upstream of seal pair, psia

$P_{d}=$ Air pressure downstream of seal pair, psia

The results of the speed ramp up and down cycle test are plotted in Fig. 11. The following observations can be made from these plots:

- The flow factor decreases as speed increases. As the speed increases, the rotor grows due to centrifugal force, therefore reducing the clearance between the seal and the rotor. Lower clearance leads to a decrease in air flow rate.

- As in the static test, the flow factor decreases as temperature increases.

- The air leakage flow begins to choke at a pressure ratio between 3 and 4 .

- For the maximum test conditions of $45000 \mathrm{rpm}$ speed, 120 psid pressure differential and $800{ }^{\circ} \mathrm{F}$ air temperature, a flow factor of less than 0.002 was measured, which is below the flow factor goal of 0.004 .

- It is feasible to extrapolate the flow factor, with reasonable accuracy, for the engine IRP operating conditions of $50000 \mathrm{rpm}$ speed, 175 psid pressure differential and $1200^{\circ} \mathrm{F}$ air temperature from the results plotted in Figs. 9 and 10. Because the flow is fully choked before the maximum rig operating condition of $45000 \mathrm{rpm}$, $120 \mathrm{psid}$ and $800^{\circ} \mathrm{F}$ is reached and because the engine IRP operating condition is higher than the rig maximum operating condition, it is reasonable to assume that the flow is also choked at the engine IRP operating condition. Therefore the flow factor at the engine IRP operating condition is expected to be similar to that at the rig maximum operating condition. It is estimated that the engine air leakage flow factor at the IRP operating conditions will be less than 0.002 for a small rotor run out of $0.0005 \mathrm{in}$., similar to that in the rig. For higher rotor run out, the flow factor is expected to increase in value. This is explored later in the rotor run out test. The leakage flow factor for the brush seal is significantly less than the leakage flow factor of 0.007 for the labyrinth seal of 0.005 in. radial clearance at the JTAGG II operating conditions.

- The seal pair (S/N 1 and 2) tested, showed considerable hysteresis as is evident in Fig. 11. This test 
was run at a constant pressure differential across the seal of 60 psid and a constant temperature of $800^{\circ} \mathrm{F}$, while speed was ramped up and then down. The air leakage flow was measured as a function of speed. The plot shows that the flow factor was higher during the ramp down cycle as compared to the ramp up cycle. It is anticipated that on the ramp up cycle bristles move out due to the rotor centrifugal growth, thermal mismatch between the seal and the rotor, rotor run out and seal offset, etc. It appears that during the ramp down cycle, the seal bristles do not return to their original position, resulting in higher leakage rates. This would imply that the frictional force between the low pressure side plate and the bristles is greater than the restoring force in the bristles.

This problem was discussed with the seal vendor EG\&G Sealol. A new set of seals (S/N 5 and 7), which incorporated their latest technology, was procured and tested later in the program (before the endurance test). These seals had two features: (1) the low pressure side plate was relieved where it contacts the bristles (similar to the conventional low hysteresis design), and (2) a thin deflector plate was inserted between the high pressure side plate and the bristles. Elements of this design are covered under U.S. patent number 5401036, but the details of some additional features proprietary to EG \& G Sealol are not available. These features have shown reduction in seal hysteresis in rig testing at EG\&G Sealol. ${ }^{1}$ Figure 2 shows a conceptual view of the advanced test seal. A photograph of the advanced low hysteresis seal is shown in Fig. 12.

The pre-endurance speed ramp up and down test results from the advanced $S / N 5$ and 7 seals are shown in Fig. 13. The difference between the flow factor at speed ramp down and ramp up is much smaller as compared to the conventional seals, S/N 1 and 2 (refer to Fig. 11).

The advanced seal pair was subjected to speed ramp up and down test after completion of $50 \mathrm{hr}$ endurance test. The results of the test are shown in Fig. 14. The seals showed evidence of hysteresis in this test similar to the conventional design (Fig. 11).

These results were discussed with the seal vendor EG\&G Sealol. At this point, an acceptable explanation for this phenomenon has been not determined. However, as per EG\&G Sealol, the advantage of advanced seal design lies in its ability to maintain a low contact load between the bristle pack and the rotor during high deflection transients like traversing through critical speeds and maneuver loads. This results in a reduction in bristle wear, therefore an increase in seal life.
Seal and Rotor Wear

The total run time accumulated during performance testing was $10.4 \mathrm{hr}$.

The post test inner diameters for seals $S / N 1$ and 2, were slightly larger than the pretest inner diameters by 0.0024 and 0.0002 in., respectively. The inner diameter change could be the result of wear, inward flowering of bristles during performance testing, and measurement errors. An optical comparator was used to measure the brush i.d at eight circumferential locations. Stray bristles, inaccuracy in locating the center of the brush, and the compliant nature of the bristles brings uncertainty to the brush i.d. measurement. This subject will require further investigation to reach a final conclusion. In spite of these uncertainties, leakage flow factor goals were met, as described earlier.

The rotor had two visible wear tracks on its mating o.d. corresponding to the two seals tested in tandem. The wear track width of $0.1181 \mathrm{in}$. was much larger than the 0.050 in. approximate bristle pack width at build. This may be a result of axial bristle movement during performance testing and the relative axial thermal movement between the bristles and the rotor. A profilometer was used to measure the rotor wear at eight approximately equally spaced circumferential locations. The wear track depth varied from 0.00021 to $0.00078 \mathrm{in}$. for track 1 and 0.00051 to $0.00119 \mathrm{in}$. for track 2 . Tracks 1 and 2 correspond to the seal on the downstream side (low pressure side, seal S/N 1) and upstream side (high pressure side, seal S/N2), respectively. The coating wear does pose some concern. This was discussed with the coating experts at EG\&G Sealol, whose proprietary Triboglide coating was used on the rotor. Triboglide, as mentioned earlier, is a chromium carbide coating with barium calcium fluoride, high temperature solid lubricant, dispersed in the coating. A further investigation revealed that the coating vendor had used a higher percentage of the solid lubricant (about 11 percent) than Sealol's recommendation (6 percent). Also the surface finish of the rotor at build ( $46 \mu \mathrm{in}$.) was much higher than the print requirement $(8 \mu \mathrm{in}$.). It is felt that improvement in wear coating and surface finish will help in reducing coating wear. ${ }^{2}$

Energy Dispersive Spectroscopy (EDS) was used to look for material transfer from the bristles to the rotor and vice versa. In the Triboglide coating the following elements can be identified: chromium, nickel, calcium and barium. The other constituents of Triboglide, carbon and fluorine, have atomic numbers that are too low to be detected on the Princeton Gama-Tech System 4 that was used. In the areas 
observed, there was no significant difference in the amount of the elements found inside or outside the tracks on the rotor, with the exception that a trace amount of Aluminum was found in the track. Aluminum is a constituent of the bristle material, Haynes 214 . Note that iron, aluminum and yitrium are the elements of Haynes 214 that are not common with Triboglide. Conversely, the elements in Triboglide that are not common with Haynes 214 are calcium, barium and fluorine. In the areas observed on bristle pack of $\mathrm{S} / \mathrm{N} 1$ and 2 seals, no calcium, barium or fluorine was found. However, since there are like elements in the bristles and rotor coating (nickel and chromium) no conclusion can be drawn stating whether the Triboglide transferred to the bristle tips or not. It does not appear that bristle material transferred to the rotor. Using the backscatter mode of the Scanning Electron Microscope (SEM), it was observed that there were less black spots in the track. In this mode on the SEM, lower atomic elements are darker and it is likely that some calcium barium fluoride has been worn from the rotor. Also through the SEM, smearing type wear was observed on the bristle tips.

\section{Brush Seal Offset Test}

This test simulates the maneuver type condition in a flight engine. In this test, each seal of the seal pair was radially offset by 0.003 in.with respect to the rotor. This was accomplished by machining a $0.003 \mathrm{in}$. radial offset in the seal adapter i.d. relative to the adapter o.d., which mates with the seal holder as shown in Fig. 3. Conventional low hysteresis brush seals $\mathrm{S} / \mathrm{N} 3$ and 4 were used as the low pressure side and high pressure side seals, respectively. Data was taken to characterize seal air leakage as a function of time. The operating conditions were $45000 \mathrm{rpm}$ speed, 60 psid air to air pressure differential and $1100^{\circ} \mathrm{F}$ air temperature for the first $10 \mathrm{hr}$, and $45000 \mathrm{rpm}$, $120 \mathrm{psid}$ and $800^{\circ} \mathrm{F}$ for the final $10 \mathrm{hr}$ of running. The seals and rotor were removed from the rig and inspected after the first $10 \mathrm{hr}$ and again after the test was completed.

\section{Leakage Performance}

Figure 15 shows a plot of air leakage flow factor as a function of accumulated run time. The steps or breaks in the data that occur every $5 \mathrm{hr}$ are indicative of taking the data over 4 run days of $5 \mathrm{hr}$ each. A slight increase in air leakage was observed with time, indicating that the clearance between the seal bristles and rotor did not change significantly in $20 \mathrm{hr}$ of running. The maximum flow factor measured was $\mathbf{0 . 0 0 2 3}$, which is below the design goal of 0.004 .

\section{Seal and Rotor Wear}

The total run time accumulated during offset testing was $20 \mathrm{hr}$.
After $10 \mathrm{hr}$ of run time, the bristle i.d. for seals S/N 3 and 4 was larger than at pretest by 0.0029 and $0.0012 \mathrm{in}$. respectively. After $20 \mathrm{hr}$ of run time, the bristle i.d. for seal S/N 3 was larger than at pretest by 0.0006 in. and for seal $\mathrm{S} / \mathrm{N} 4$ seal was smaller by $0.0014 \mathrm{in}$. A possible explanation for this could be that bristles flowering inwards compensated for wear on the bristles as the run time got closer to $20 \mathrm{hr}$. However, as mentioned earlier, the brush seal i.d. measurement can not be accurately made. In spite of these uncertainties, leakage flow factor goals were met, as described earlier.

The wear track width of $0.15 \mathrm{in}$. was much larger than the $0.050 \mathrm{in}$. approximate bristle pack width at build. This may be due to axial bristle movement during offset testing and the relative thermal axial movement between the bristles and the rotor.

The wear track depth, after $10 \mathrm{hr}$ of run time, varies from 0.00009 to $0.0010 \mathrm{in}$. for track 1 and 0.00005 to $0.00017 \mathrm{in}$. for track 2 . The wear track depth, after $20 \mathrm{hr}$ of run time, varies from 0.0002 to 0.001 in. for track 1 and 0.00001 to $0.00018 \mathrm{in}$. for track 2. Rotor wear in the seal offset test was less than the rotor wear in the performance test, which may be due to the finer surface finish $(8 \mu \mathrm{in}$.) of the rotor used in the seal offset test. The rotor wear seems acceptable, since the seal leakage flow factor did not change significantly after $20 \mathrm{hr}$ of run time.

\section{$\underline{\text { Rotor Run Out Test }}$}

This test simulated the transient conditions in a flight engine, such as traversing through critical speeds and fast accelerations and decelerations, etc. The rotor o.d. had a radial run out of 0.003 in. with respect to its i.d. pilot. Conventional low hysteresis brush seals $\mathrm{S} / \mathrm{N} 6$ and 8 were used in this test as the low pressure side and high pressure side seals, respectively. Data was taken to characterize the seal air leakage as a function of run time. During the first $10 \mathrm{hr}$ the operating conditions were $40000 \mathrm{rpm}$ speed, $60 \mathrm{psid}$ air to air pressure differential and $1100{ }^{\circ} \mathrm{F}$ air temperature. Then the seals and rotor were removed from the rig and inspected. After reinstallation, testing continued at operating conditions of $40000 \mathrm{rpm}, 95$ to $100 \mathrm{psid}$ across the seal, and $800^{\circ} \mathrm{F}$ inlet air temperature for another $10 \mathrm{hr}$. The seal and rotor were removed from the rig and given a final inspection. Although trim balanced, $40000 \mathrm{rpm}$ was the maximum shaft speed obtainable with the $0.003 \mathrm{in}$. radial run out in the rotor, due to rig vibration limits.

\section{Leakage Performance}

Figure 16 shows a plot of air leakage flow factor as a function of time. The leakage flow factor approximately 
doubled, from about 0.002 to 0.004 , after $5 \mathrm{hr}$ of running. In the next $15 \mathrm{hr}$ of running, leakage flow factor increased slightly to a little over 0.004 . It can be concluded that after $5 \mathrm{hr}$ of running, the flow factor stabilized. These results also indicate that rotor run out had a much more pronounced effect on air leakage as compared to seal offset. Again, the steps in the data reflect the four $5 \mathrm{hr}$ run days.

\section{Seal and Rotor Wear}

The total run time accumulated during rotor run out testing was $20 \mathrm{hr}$.

After $10 \mathrm{hr}$ of run time, the bristle i.d. for seals S/N 6 and 8 was larger than at pretest by 0.0082 and 0.0027 in., respectively. After $20 \mathrm{hr}$ of run time, the bristle i.d. for seals S/N 6 and 8 was larger than at pretest i.d. by 0.0064 and 0.0012 in., respectively. A possible explanation for this could be that the bristle flowering inwards was larger than the bristle wear as run time approached $20 \mathrm{hr}$. In spite of the uncertainty in the brush seal i.d. measurement, the increase in the brush seal i.d. for the rotor run out test was significantly more than for previous tests.

The rotor, which had an initial surface finish of 21 to $23 \mu$ in., showed wear as well as material build up in its wear tracks. The maximum groove depth in wear tracks 1 and 2 after $10 \mathrm{hr}$ of run time was 0.00052 and $0.00087 \mathrm{in}$., respectively. The maximum build up in wear tracks numbers 1 and 2 after $10 \mathrm{hr}$ of run time was 0.00068 and $0.00059 \mathrm{in}$., respectively. The maximum groove depth in wear tracks 1 and 2 after $20 \mathrm{hr}$ of run time was 0.00092 and $0.00088 \mathrm{in}$., respectively. The maximum build up in wear tracks 1 and 2, after $20 \mathrm{hr}$ of run time, was 0.00055 and 0.0005 in., respectively. The maximum groove depth occurred at the same location as the maximum rotor run out. The maximum build up occurred at $90^{\circ}$ from the maximum groove depth. The build up on the rotor is indicative of metal transfer.

EDS plots for the rotor after twenty hours run time showed the presence of aluminum in both the low and high pressure side wear tracks on the rotor. Aluminum is an element found in Haynes 214 bristle material, but not found in Triboglide coating on the rotor. Based on this evidence and build up of material seen on the rotor wear tracks, it can be concluded that Haynes 214 bristle material transferred to the rotor.

The effect of material transfer on seal performance is difficult to assess. However, as mentioned earlier, leakage flow factor increased from $\sim 0.002$ to 0.004 after $5 \mathrm{hr}$ of run time and then remained close to the leakage flow factor goal of 0.004 for the remaining $15 \mathrm{hr}$ of the test. Though the testing was limited to $20 \mathrm{hr}$, the results indicate that brush seals have good potential for long life applications.

\section{Endurance Test}

A $50 \mathrm{hr}$ endurance test was conducted to evaluate the long term air leakage characteristics of the brush seal. Advanced low hysteresis brush seals S/N 5 and 7 were used in this test as the low pressure side and high pressure side seals, respectively. This test was conducted at operating conditions of $45000 \mathrm{rpm}$ speed, $60 \mathrm{psid}$ air to air pressure differential and $1100^{\circ} \mathrm{F}$ air temperature for the first $25 \mathrm{hr}$ and $45000 \mathrm{rpm}, 90$ to $103 \mathrm{psid}$ and $800^{\circ} \mathrm{F}$ for the final $25 \mathrm{hr}$ of running. The seals and rotor were inspected after the first $25 \mathrm{hr}$ of testing and again at test completion.

\section{Leakage Performance}

Figure 17 shows a plot of air leakage flow factor as a function of time. There was no significant change in flow factor after $50 \mathrm{hr}$ of run time. The flow factor was close to 0.002 for the entire duration of the endurance test. This is well below the flow factor goal of 0.004 .

\section{Seal and Rotor Wear}

The total run time accumulated during endurance testing was $\mathbf{5 0} \mathrm{hr}$.

After $25 \mathrm{hr}$ of run time, the bristle i.d. for seal S/N 5 seal was larger by 0.0024 and for seal $\mathrm{S} / \mathrm{N} 7$ was smaller by $0.00145 \mathrm{in}$. After $50 \mathrm{hr}$ of run time, the bristle i.d. for seals $\mathrm{S} / \mathrm{N} 5$ and 7 was smaller than at pretest by 0.0051 and 0.0052 in., respectively. A possible explanation for this could be that bristle flowering is larger than bristle wear. However, as mentioned earlier, the brush seal i.d. measurement can not be made accurately. It was fairly consistently observed that the standard deviation of the brush seal i.d. measurements increased as run time was accumulated.

Visual inspection showed that several rows of bristles protrude radially inwards more than their neighboring bristles over two 30 to $40^{\circ}$ sectors on brush seal S/N 5 and over an $\sim 90^{\circ}$ sector on brush seal S/N 7. Therefore change in brush i.d. is not a good indicator of bristle wear, but in this case indicates inward flowering of the bristles.

Since the i.d. measurement was not a good indicator of bristle wear, a method developed by Fellenstein ${ }^{3}$ was adopted. In this method the low pressure side plate of each brush seal was marked in four equally spaced circumferential locations. Prior to endurance testing, calibrated magnified photographs were taken of the bristle length extending beyond the low pressure side plate and of the 
bristle length extending beyond the deflector plate on the high pressure side at each of the marked locations. Photographs were taken again after testing. Pretest and post-test bristle angle and length were measured from the photographs to determine bristle wear. Visual averaging of bristle lengths was used where necessary. Data from the sector where bristles were extending in radially were excluded from the average of bristle wear. The average bristle wear was 0.023 and $0.016 \mathrm{in}$. on the low pressure side and 0.013 and $0.009 \mathrm{in}$. on the high pressure side of brush $\mathrm{S} / \mathrm{N} 5$ and 7 , respectively. The bristle angle change was $2.3^{\circ}$ for seal $\mathrm{S} / \mathrm{N} 5$ and $1.5^{\circ}$ for seal $\mathrm{S} / \mathrm{N} 7$. Since measurements indicate that flowering compensates for the considerable bristle wear over the $50 \mathrm{hr}$ test time, it is concluded that the clearance did not change significantly. This is also evidenced by the small change in leakage flow factor over the test duration.

The rotor, which had an initial surface finish of $24.3 \mu$ in., showed no grooves, but only material build up in its wear tracks. The maximum build up in wear tracks 1 and 2 after 25 hr of run time was 0.00152 and 0.00041 in., respectively. The maximum build up in wear tracks 1 and 2 after $50 \mathrm{hr}$ of run time was 0.00078 and $0.00031 \mathrm{in}$., respectively. The maximum buildup of material on the tracks has decreased from the buildup value after the first $25 \mathrm{hr}$ of run time. The amount of buildup is small and does not have any significant impact on the seal performance, as is evident from the relatively constant flow factor of $\sim 0.002$ for the entire duration of the endurance test.

Aluminum, an element in the Haynes 214 bristle material, but not in the Triboglide coating, was found in both rotor wear tracks after 25 and $50 \mathrm{hr}$ of testing through EDS analysis. Based on this evidence and the profilometer traces which showed material build up in rotor wear tracks, it can be concluded that the Haynes 214 bristle material transferred to the rotor. Also, some hairline cracks were found in the coating material on the low pressure side of the low pressure track; the cracks were parallel and in the axial direction. EDS was also done on one brush seal, S/N 5, to examine the bristle tips. Some debris was found which contained calcium, which means the debris may be Triboglide. However, there are otherelements in the debris that may indicate it is just dirt picked up from handling.

\section{Conclusions}

1. Based on the extrapolated test results, the brush seal design should be able to meet the air leakage flow factor goal of less than 0.004 for the engine operating conditions. This is a significant improvement over the leakage flow factor of 0.007 for a labyrinth seal with a 0.005 in. radial clearance.
2. The excellent condition of and low wear observed on the post test seals and rotors indicate that the brush seals have an excellent potential for long life applications.

3. Some material transfer occurred between the seal bristles and the rotor coating; however, the material transfer was small.

4. Both the conventional and advanced seal designs showed considerable hysteresis. Further research is recommended to reduce seal hysteresis. This will help further reduce the seal air leakage flow rate.

5. Rotor and seal wear and leakage performance were more effected by rotor run out than by seal offset.

6. The leakage flow factor decreases as speed and temperature increase due to a reduction in seal clearance and increased air viscosity.

7. Air leakage flow began to choke at pressure ratios between 3 and 4 .

8. In the endurance test, the bristle wear was compensated by inward flowering of the bristles, resulting in minimal clearance change and, therefore, only a small change in leakage flow factor over $50 \mathrm{hr}$ of testing.

9. Both brush i.d. and bristle wear measurements should be made to assess bristle flowering and wear in brush seals.

\section{Acknowledgments}

The work described in this paper reflects efforts supported by the Tri-services JTAGG program of the U.S. Army, Aviation Applied Technology Directorate(AATD), Naval Air System Command Propulsion and Power Engineering Dept. (AIR4.4), and Wright Laboratories Aero-propulsion and Power Directorate (WL/PO). The AATD program manager is Sandra Hoff and the mechanical components technical monitor is Phil LaFarriere for the JTAGG II program.

The authors acknowledge the contributions of NASA Lewis Research Center, Cleveland, $\mathrm{OH}$, where all the testing was conducted and the operations support of Joseph Flowers of the Army Research Laboratory, Vehicle Technology Center-Lewis Site. The authors also thank EG\&G Sealol, Engineered Products Division, Warwick, RI, where all the test seals were fabricated. 


\section{References}

1. Short, J.F., Basu, P., Datta, A., Loewenthal, R.G., Prior, R.J., "Advanced Brush Seal Development," AIAA Paper No. 96-2907, 1996.

2. Ferguson, J.G., "Brushes as High Performance Gas Turbine Seals," ASME Paper 88-GT-182, 1988.
3. Fellenstein, J.A., "A New Tribological Test for Candidate Brush Seal Materials Evaluation,"NASA TM-106753, 1995.

TABLE I--NASA RIG TEST AND JTAGG II ENGINE OPERATING CONDITIONS

\begin{tabular}{|l|c|c|c|c|}
\hline \multicolumn{1}{|c|}{ Operating condition } & NASA rig & NASA rig & NASA rig & $\begin{array}{c}\text { JTAGG II } \\
\text { engine }\end{array}$ \\
\hline Maximum speed, rpm (ft/sec) & $45000(809)$ & $45000(809)$ & $45000(809)$ & $\begin{array}{c}50000 \\
(899)\end{array}$ \\
\hline $\begin{array}{l}\text { Maximum air to air pressure } \\
\text { differential, psid }\end{array}$ & 60 & 120 & 145 & 175 \\
\hline Maximum air temperature, $^{\circ} \mathrm{F}$ & 1100 & 800 & 70 & 1200 \\
\hline
\end{tabular}

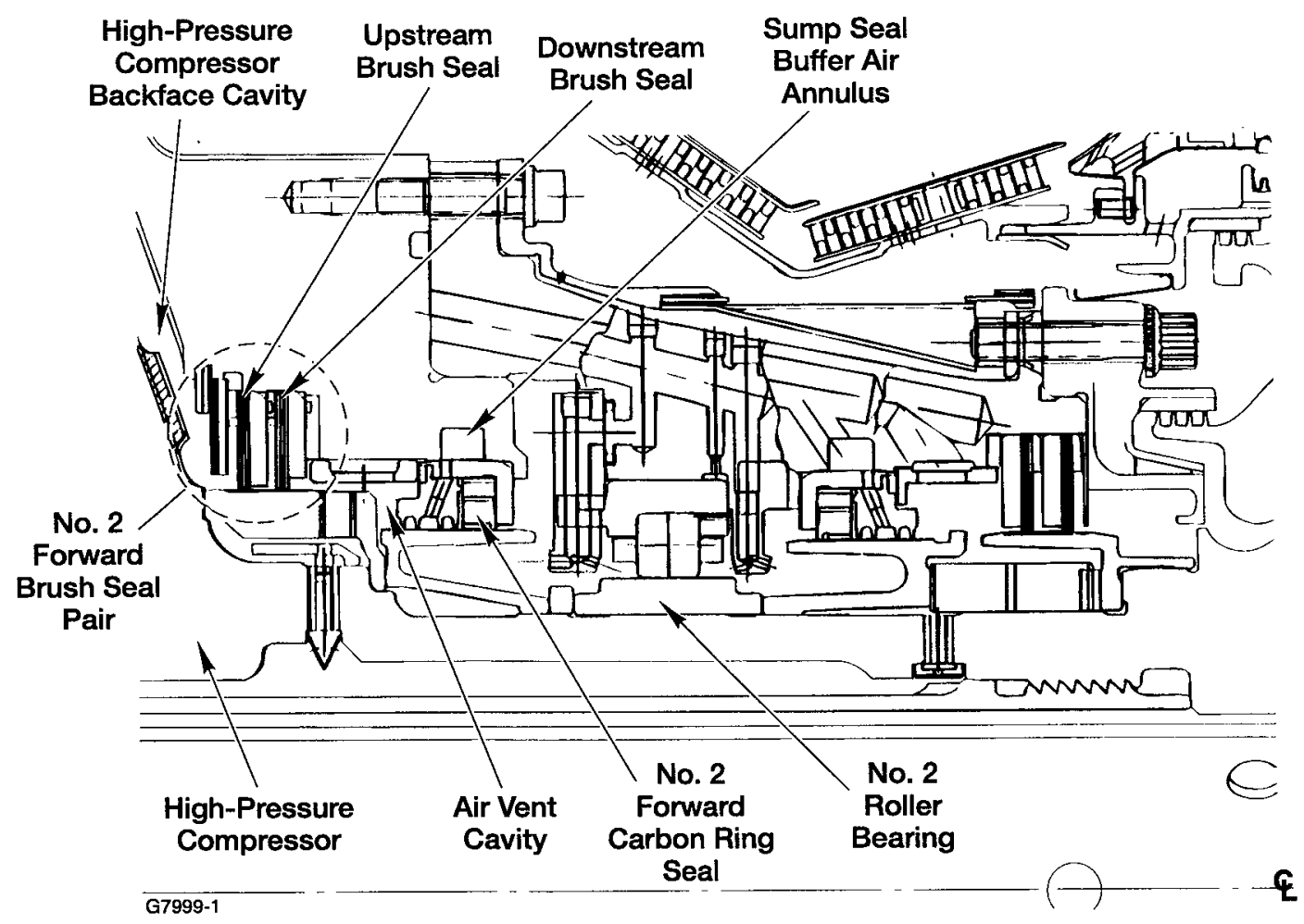

Figure 1. JTAGG II No. 2 forward brush seal arrangement. 
(3)

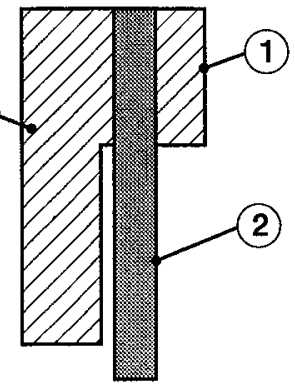

Conventional low-hysteresis design (S/N 1, 2, 3, 4, 6, and 8)

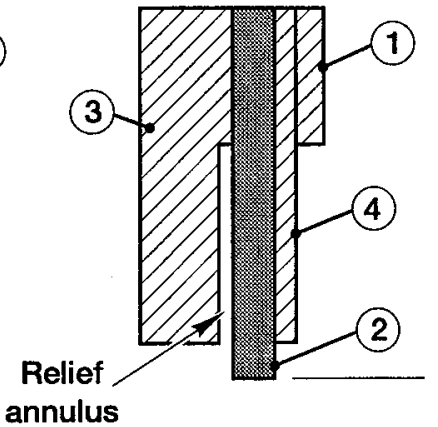

Advanced low-hysteresis design (S/N 5 and 7)

1. High-Pressure Side Plate, INCO 625

2. Bristle Pack, Haynes 214, Bristle Diameter 0.0028 Inch

3. Low-Pressure Side Plate, INCO 625

4. Deflector Plate, INCO 625

Figure 2.-JTAGG II Typical test brush seal and its nomenclature.

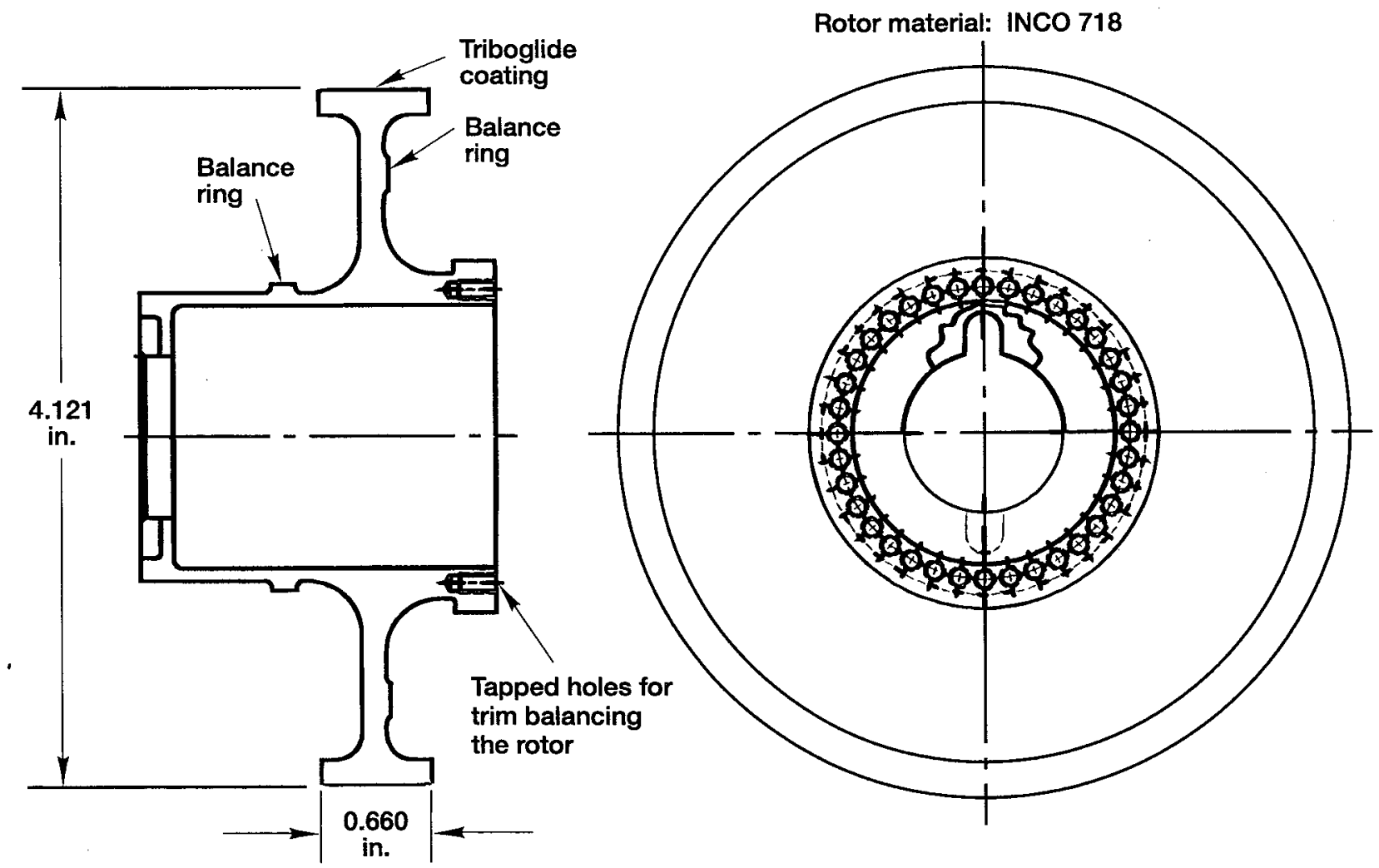

Figure 3.-JTAGG II Brush seal rig test rotor. 


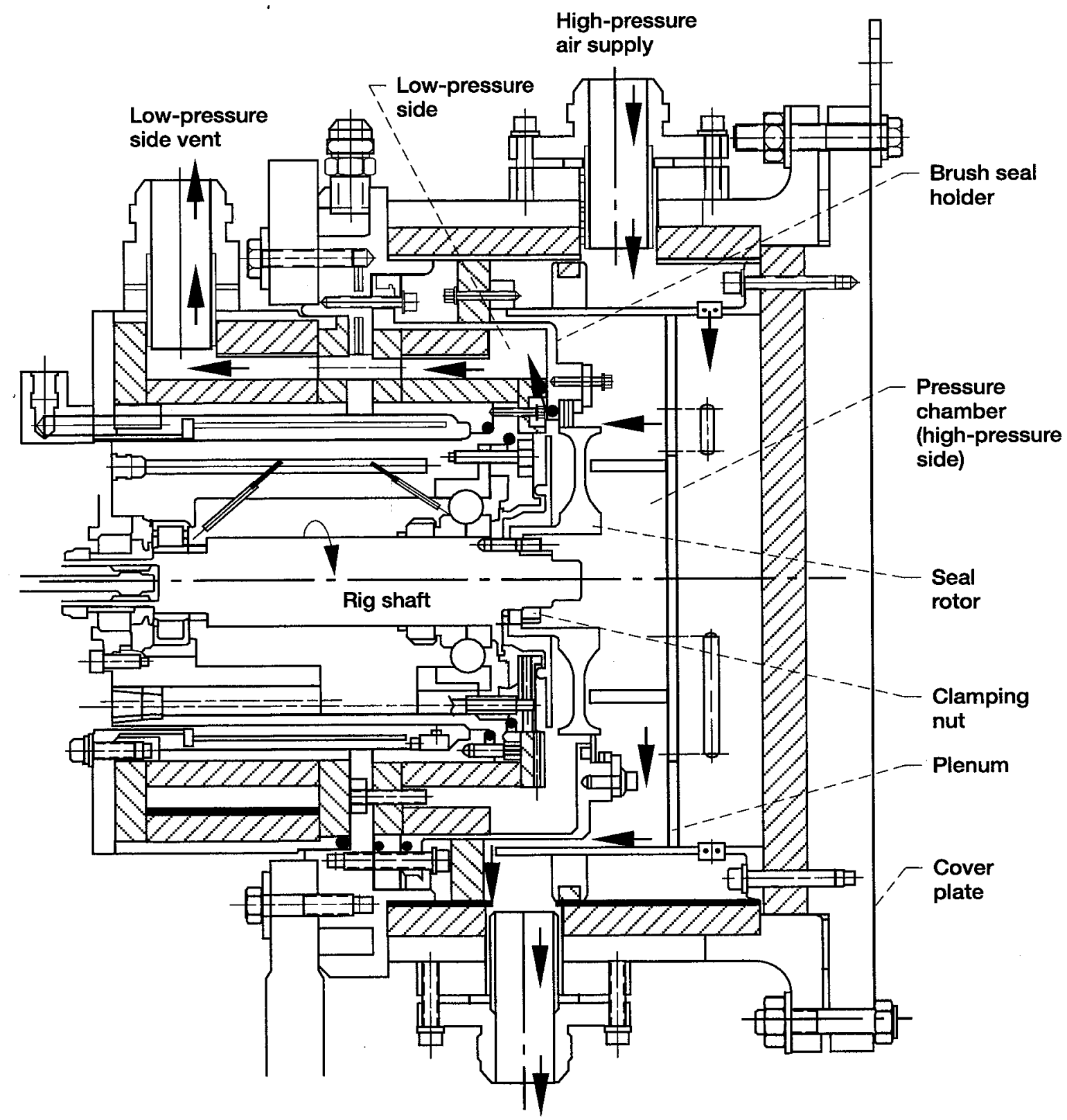

Figure 4.-NASA Lewis seal rig cross section. 


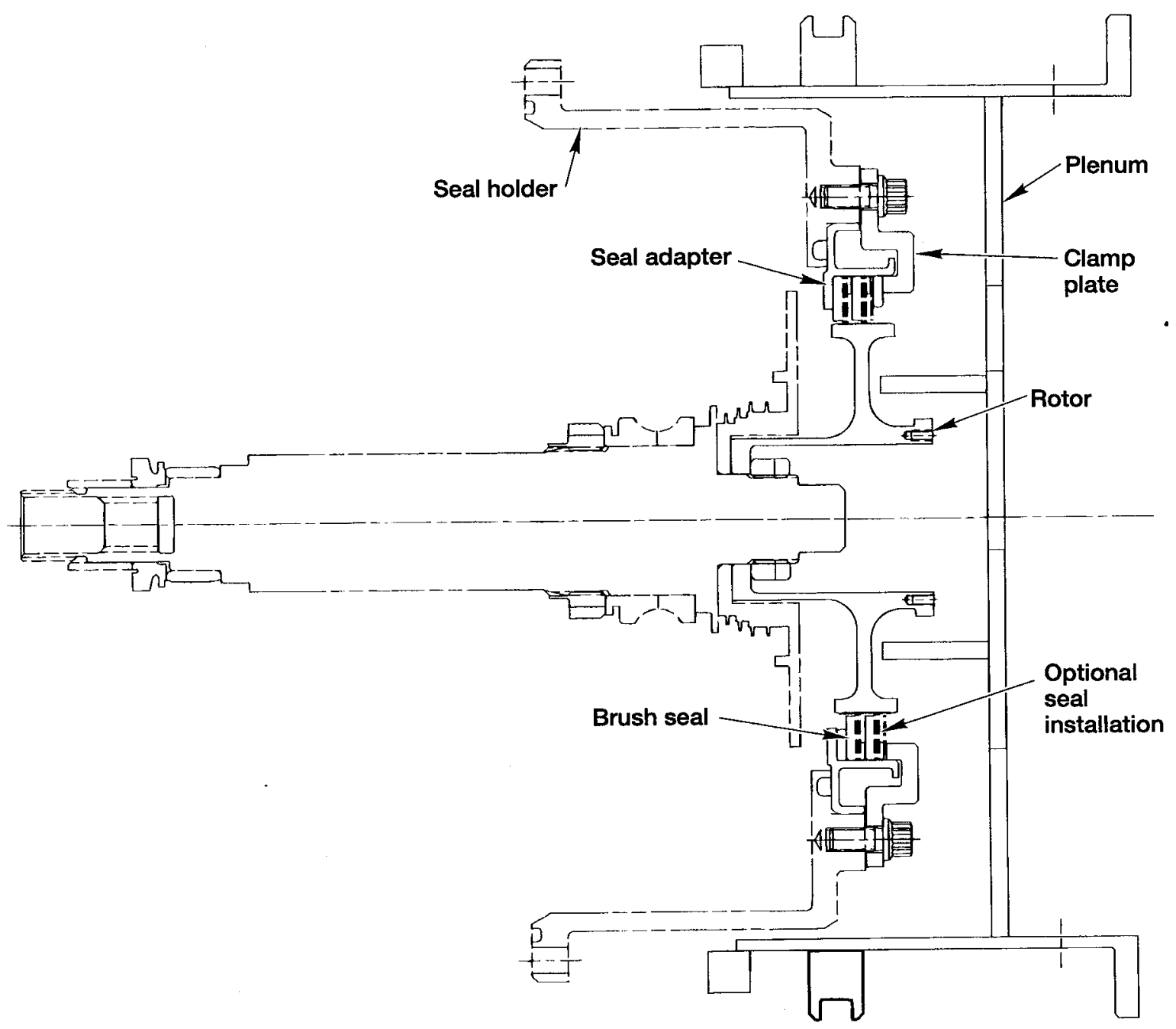

Figure 5.-NASA Lewis seal rig brush seal and rotor installation for JTAGG II. 


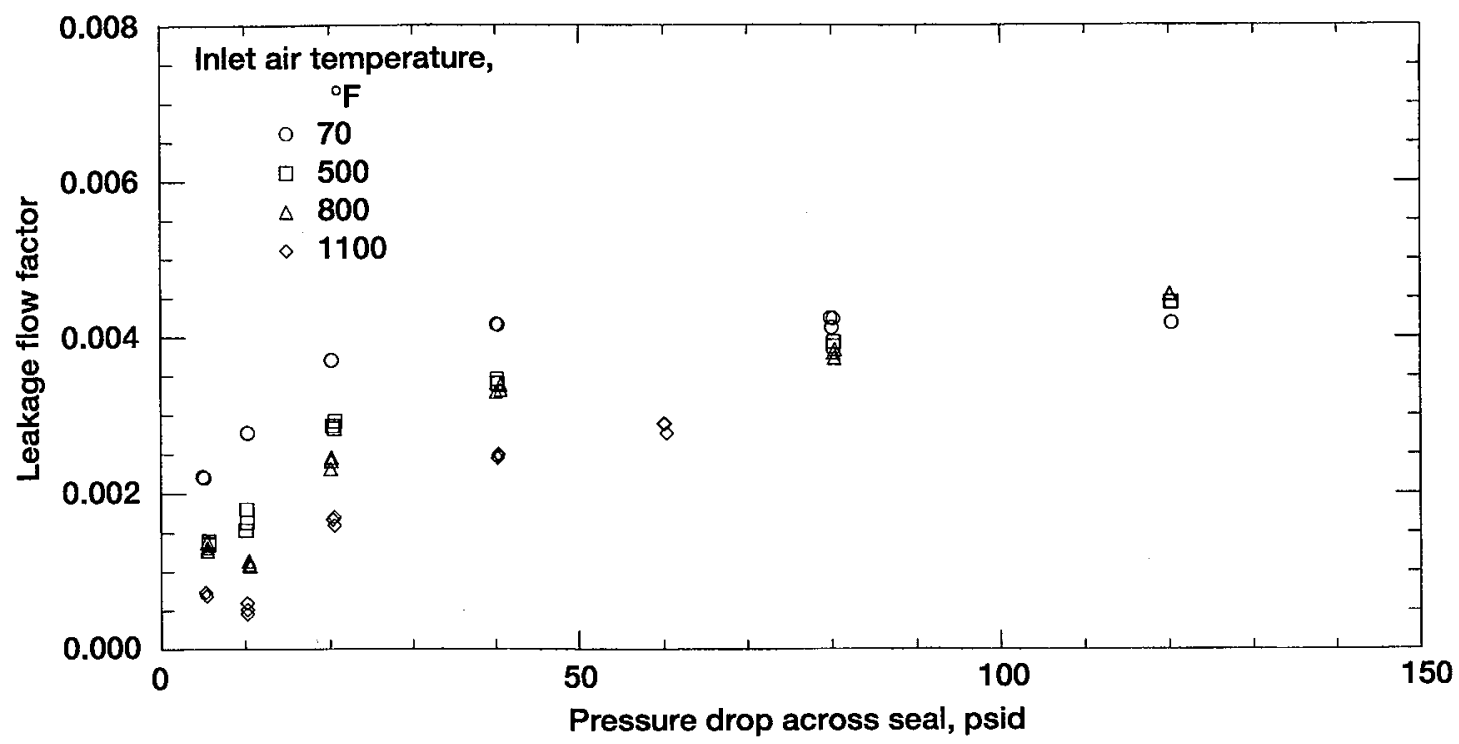

Figure 6.-Static test: leakage flow factor vs. pressure drop across seal as a function of inlet air temperature. Conventional low hysteresis brush seals, S/N 1 and 2.

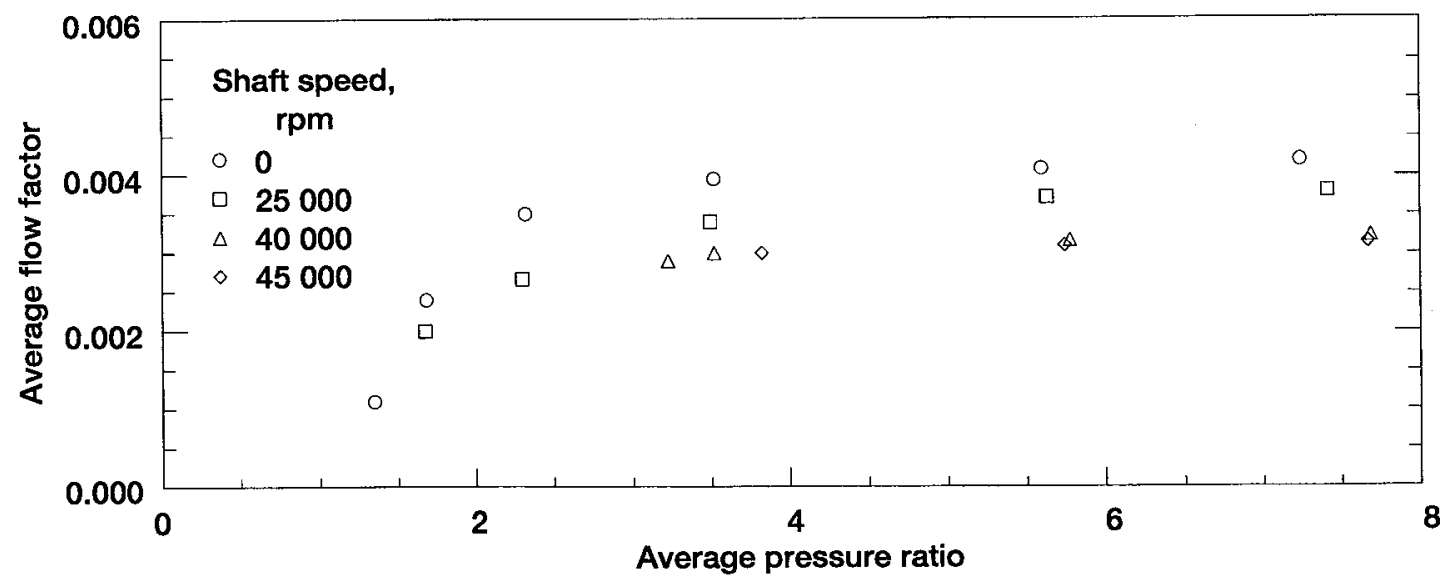

Figure 7.-Performance test: average flow factor vs. average pressure ratio as a function of speed at $70^{\circ} \mathrm{F}$ inlet air temperature. Conventional low hysteresis brush seals, S/N 1 and 2. 


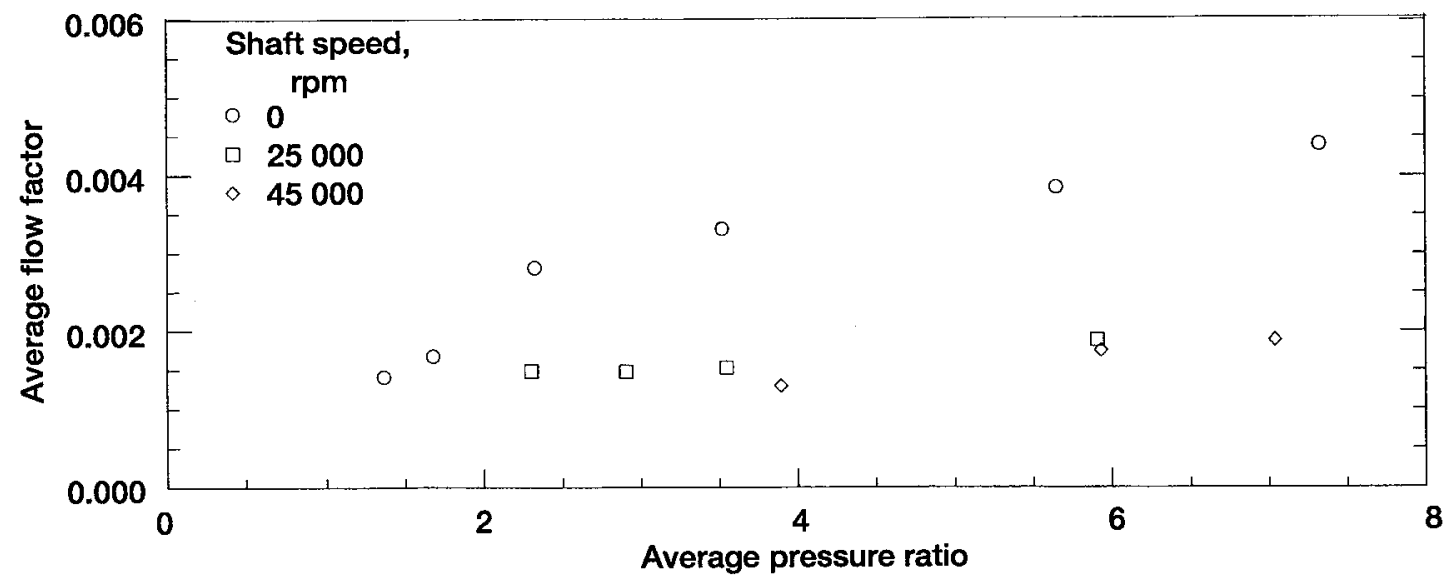

Figure 8.-Performance test: average flow factor vs. average pressure ratio as a function of speed at $500^{\circ} \mathrm{F}$ inlet air temperature. Conventional low hysteresis brush seals, S/N 1 and 2.

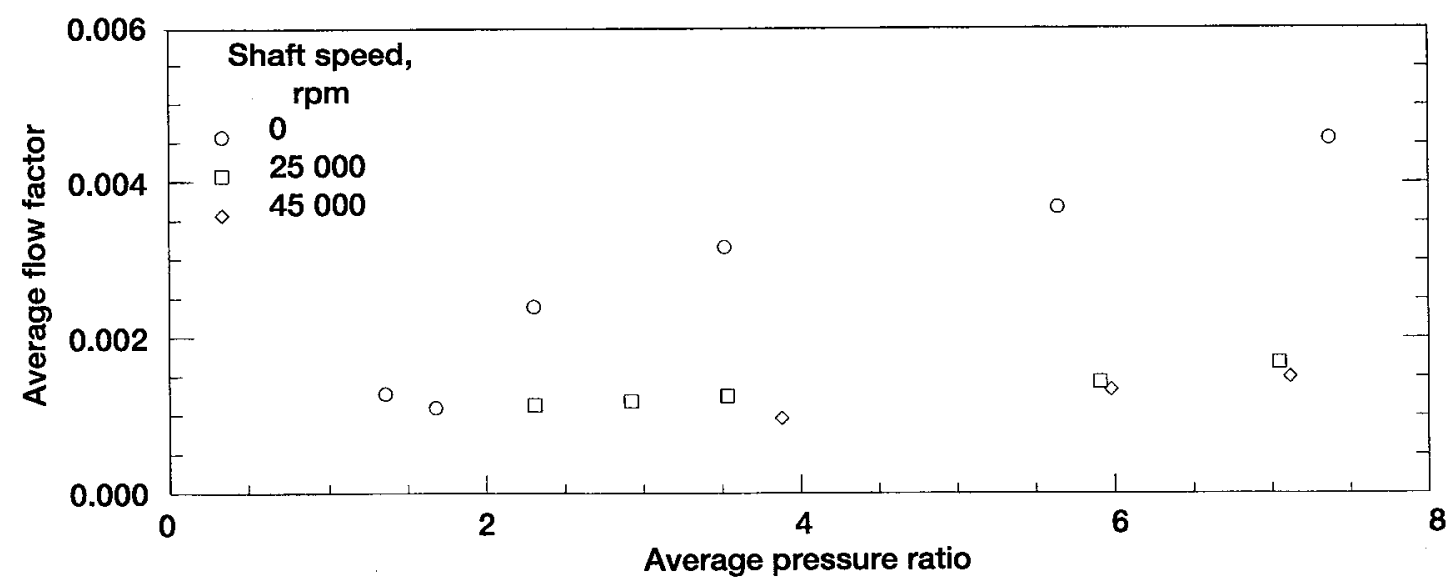

Figure 9.-Performance test: average flow factor vs. average pressure ratio as a function of speed at $800^{\circ} \mathrm{F}$ inlet air temperature. Conventional low hysteresis brush seals, S/N 1 and 2.

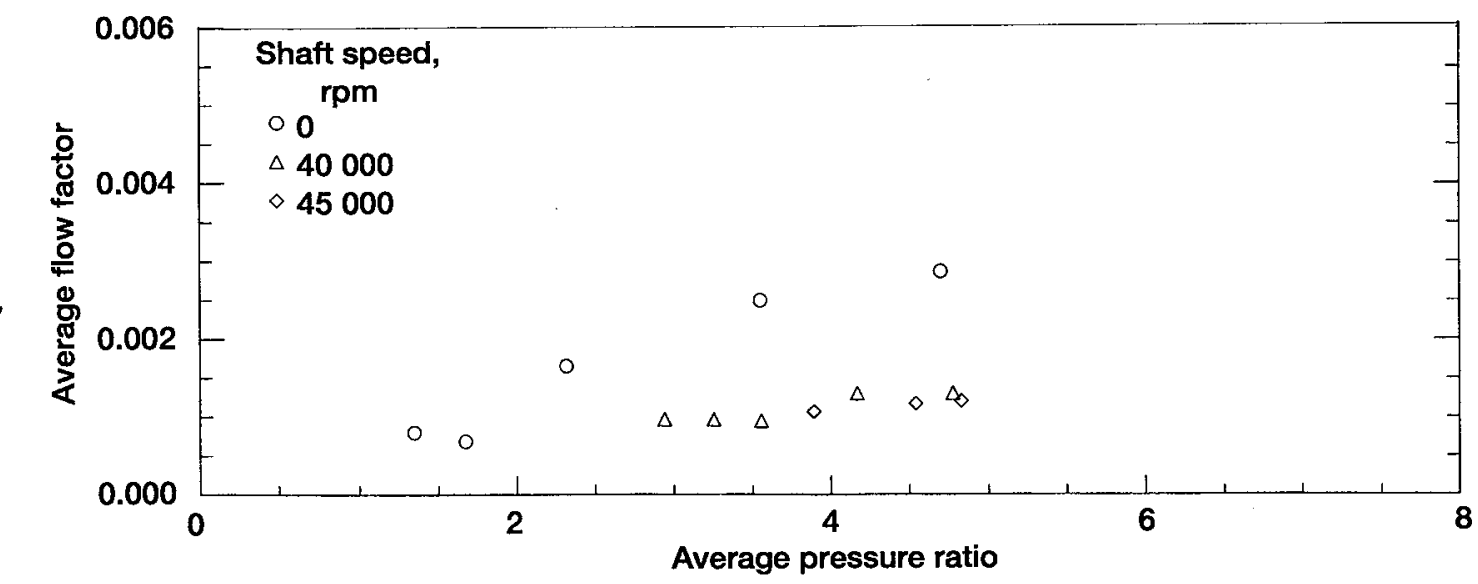

Figure 10.-Performance test: average flow factor vs. average pressure ratio as a function of speed at $1100^{\circ} \mathrm{F}$ inlet air temperature. Conventional low hysteresis brush seals, S/N 1 and 2. 


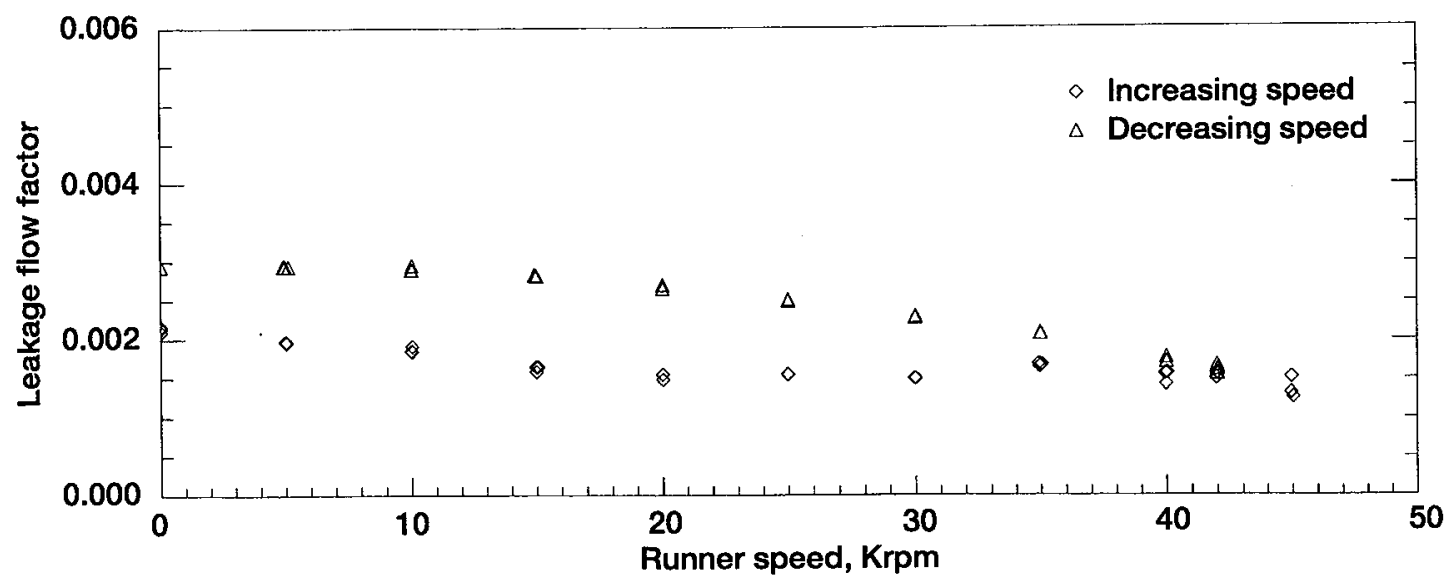

Figure 11.-Effect of speed ramp up and down on leakage flow factor on conventional low hysteresis brush seals, $\mathrm{S} / \mathrm{N} 1$ and 2 . Inlet air temperature, $800^{\circ} \mathrm{F}$; pressure drop across seals, 60 psid.

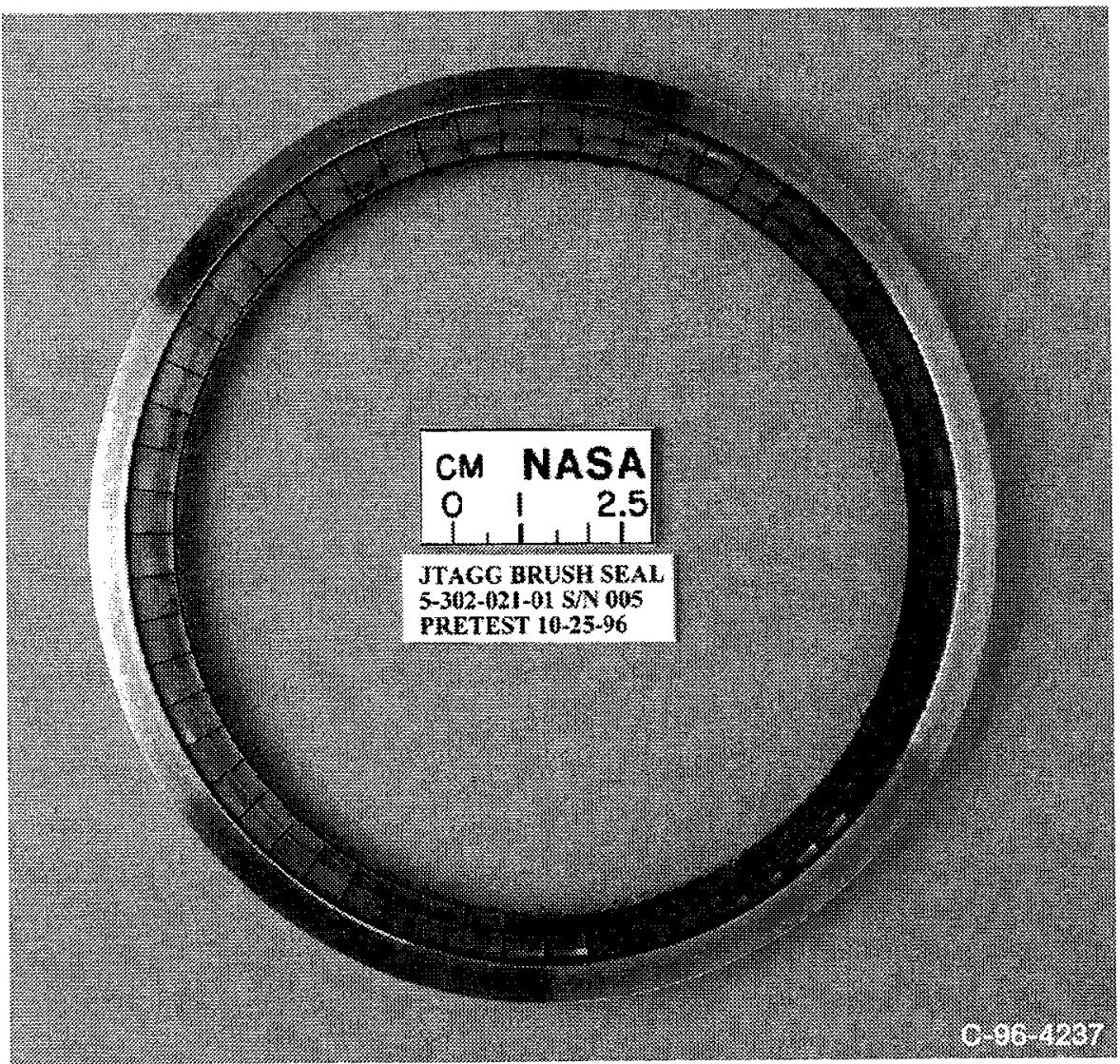

Figure 12.-Advanced low hysteresis brush seal. 


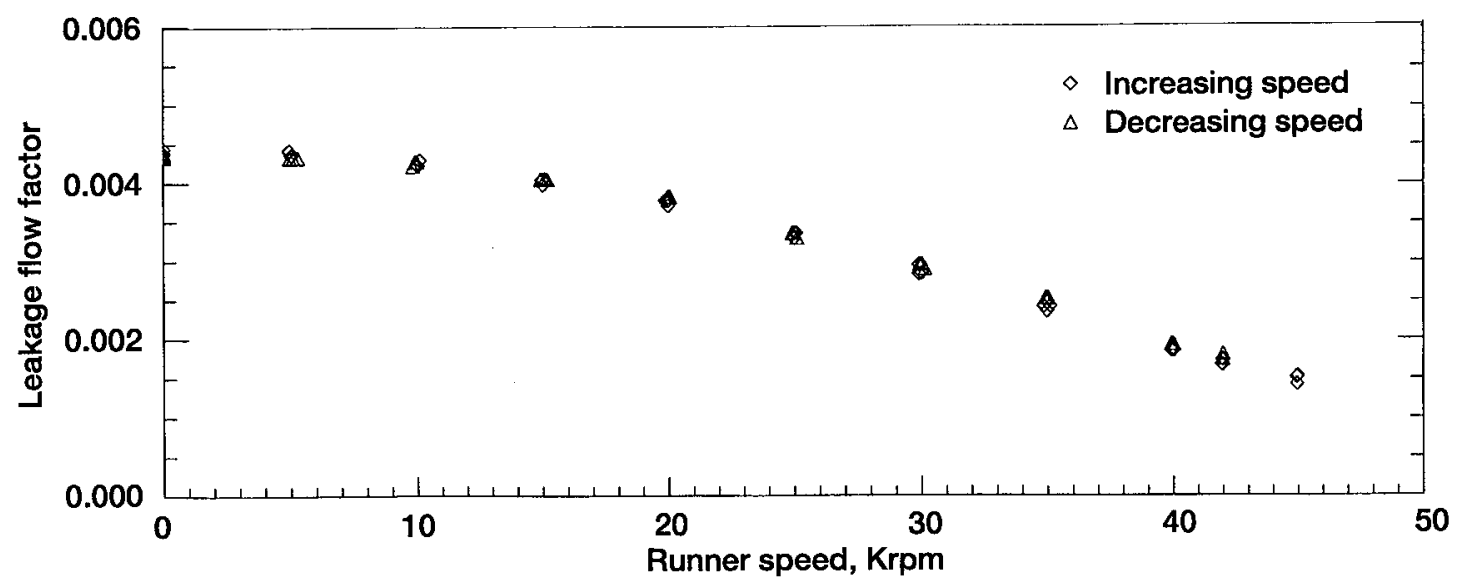

Figure 13.-Effect of speed ramp up and down on leakage flow factor for advanced low hysteresis brush seals, S/N 5 and 7, prior to endurance test. Inlet air temperature, $800^{\circ} \mathrm{F}$; pressure drop across seals, 60 psid.

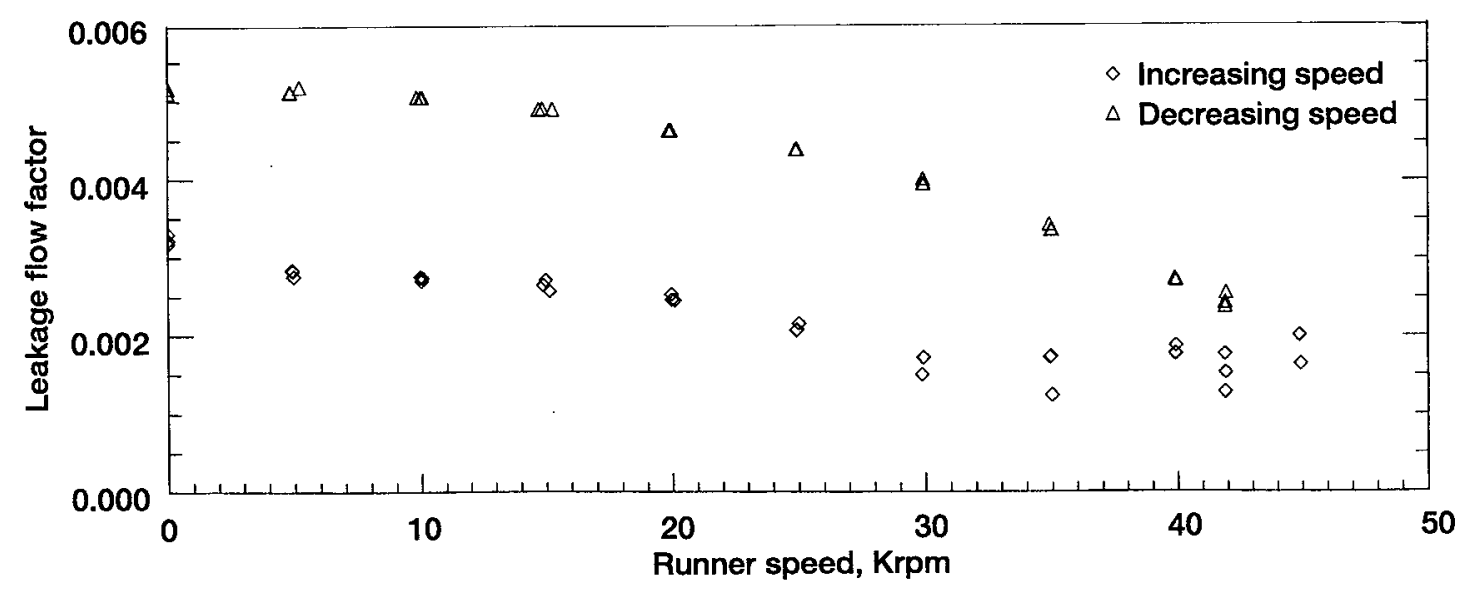

Figure 14.-Effect of speed ramp up and down on leakage flow factor for advanced low hysteresis brush seals, S/N 5 and 7, after endurance test. Inlet air temperature, $800^{\circ} \mathrm{F}$; pressure drop across seals, 60 psid.

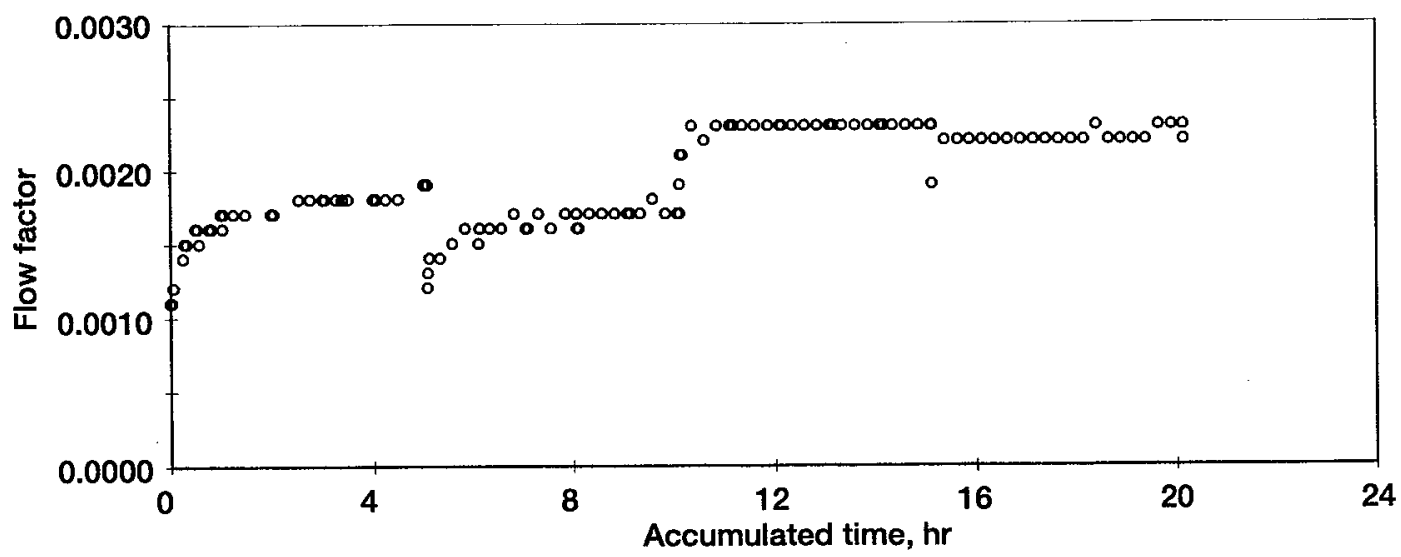

Figure 15.-Seal offset test: flow factor vs. accumulated run time. Conventional low hysteresis brush seals, S/N 3 and 4 . 


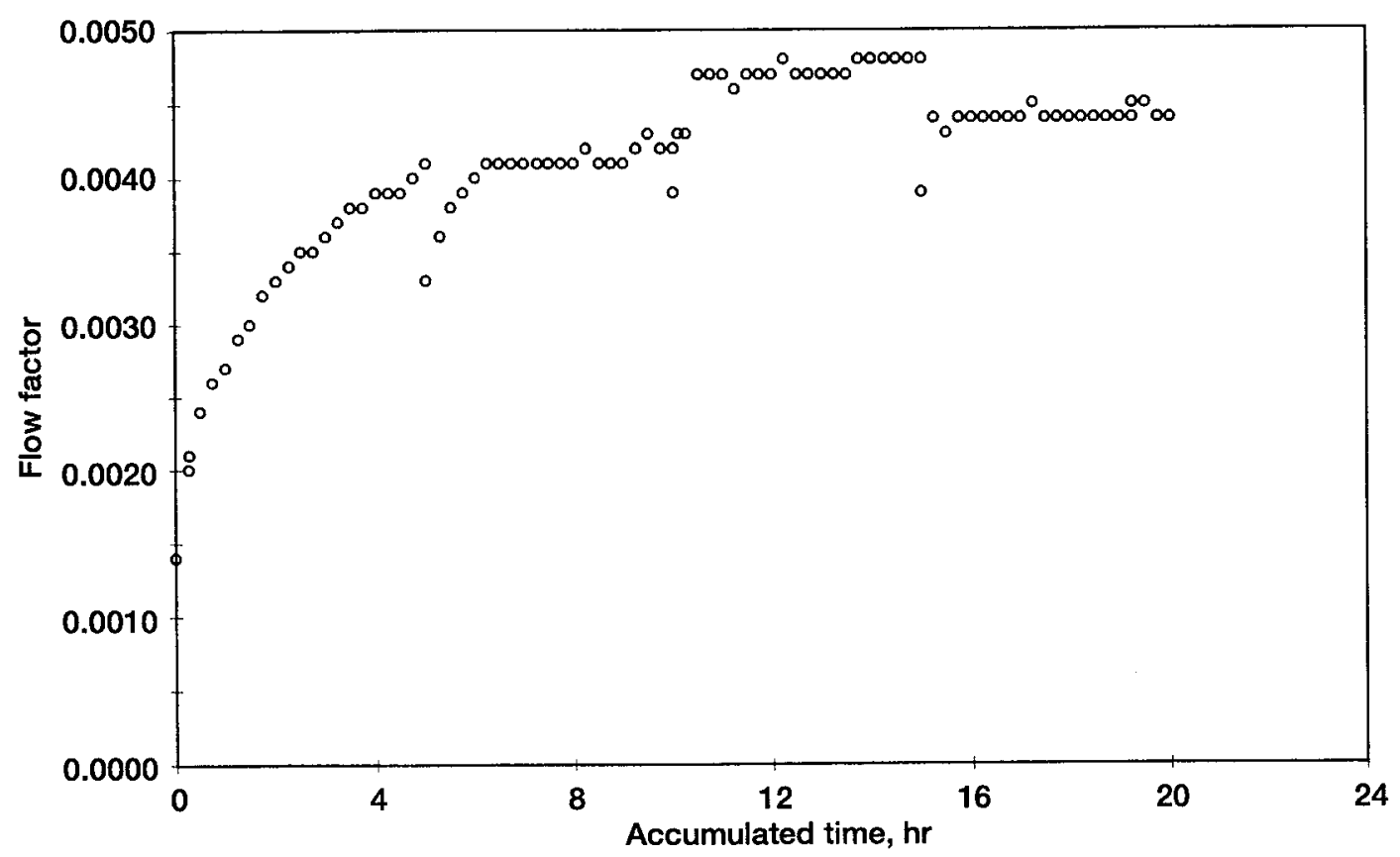

Figure 16.-Rotor runout test: flow factor vs. accumulated run time. Conventional low hysteresis brush seals, S/N 6 and 8.

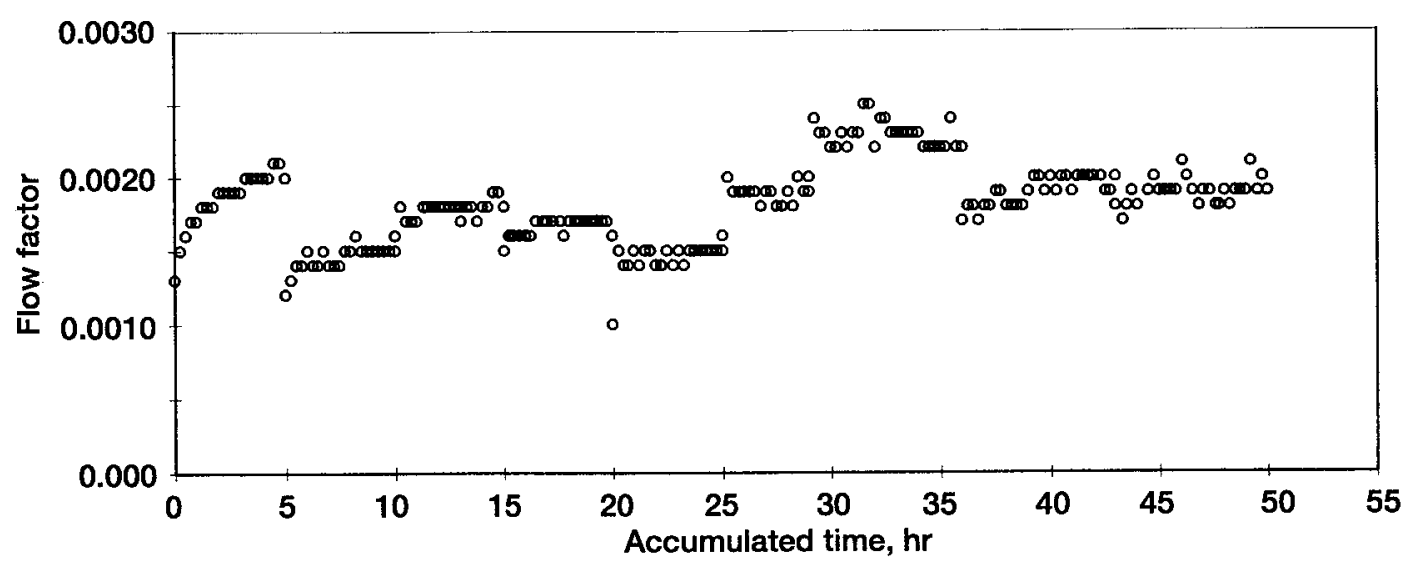

Figure 17.-Endurance test: flow factor vs. accumulated run time. Advanced low hysteresis brush seals, S/N 5 and 7. 


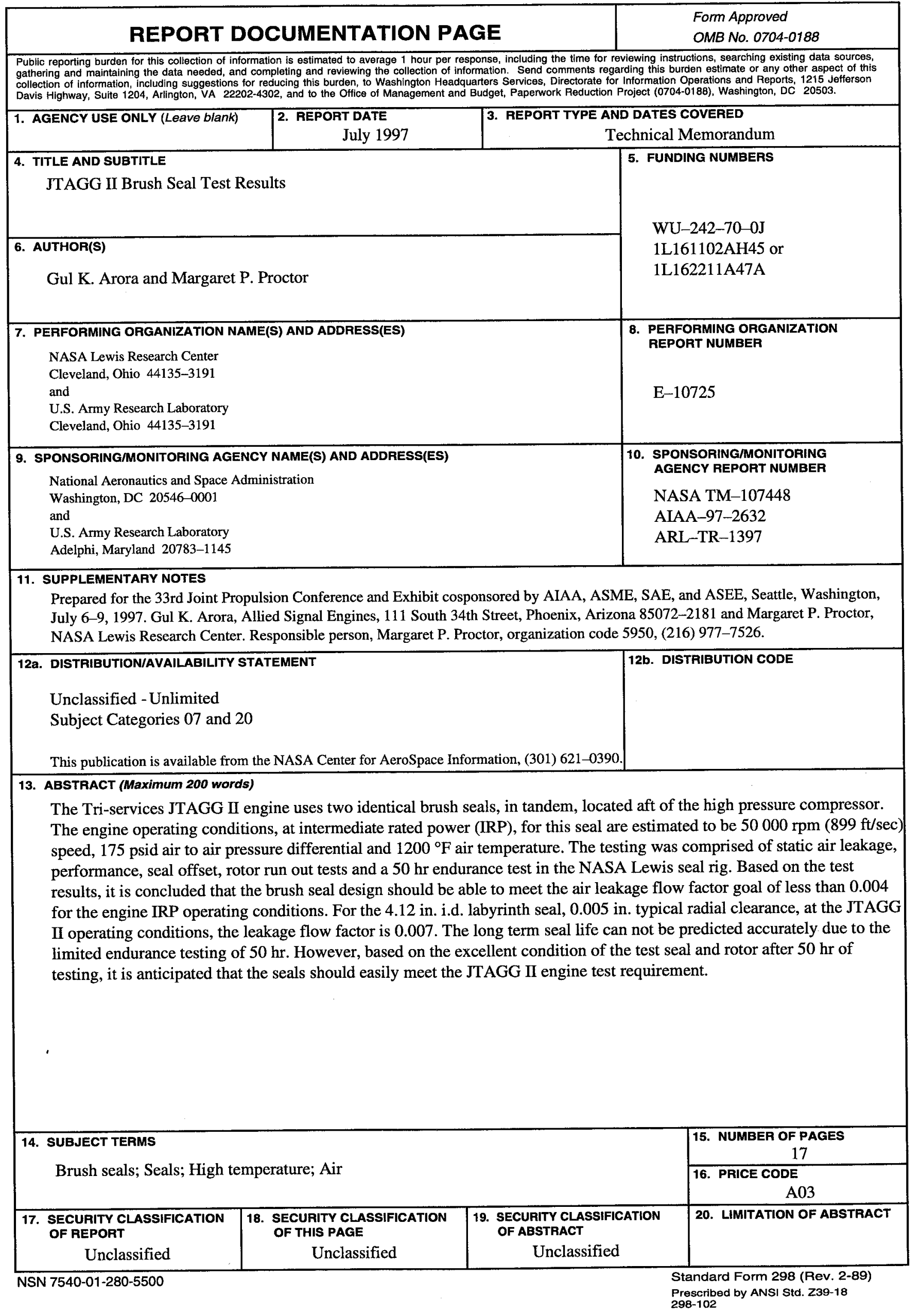

